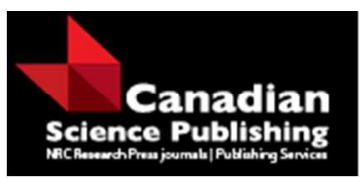

Canadian Journal of Forest Research Revue canadienne de recherche forestière

\title{
Development of cryopreservation methods for cherry birch (Betula lenta L.), an endangered tree species in Canada
}

\begin{tabular}{|r|l|}
\hline Journal: & Canadian Journal of Forest Research \\
\hline Manuscript ID & cjfr-2016-0166.R1 \\
\hline Danuscript Type: & Article \\
\hline Complete List of Authors: & $\begin{array}{l}\text { Rathwell, Ricki; University of Gueph, Plant Agriculture } \\
\text { Popova, Elena; University of Guelph, Department of Plant Agriculture } \\
\text { Shukla, Mukund; University of Guelph, Plant Agriculture } \\
\text { Saxena, Praveen; University of Guelph, Plant Agriculture }\end{array}$ \\
\hline Keyword: & $\begin{array}{l}\text { Betula lenta, cryopreservation, droplet-vitrification, shoot tips, } \\
\text { encapsulation-vitrification }\end{array}$ \\
\hline & \\
\hline
\end{tabular}




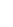

\section{Development of cryopreservation methods for cherry birch (Betula lenta}

\section{L.), an endangered tree species in Canada}

Ricki Rathwell, Elena Popova, Mukund R. Shukla, Praveen K. Saxena*

Gosling Research Institute for Plant Preservation, Department of Plant Agriculture, University of Guelph, Guelph, ON N1G 2W1, Canada.

*Corresponding author: psaxena@uoguelph.ca

\section{Abstract}

Cherry birch (Betula lenta L.) is an endangered species in Canada with only a single natural population of 18 trees found in the Niagara region of Ontario. The tree was reportedly used as a medicine by First Nations and Native American peoples. The current study describes a cryopreservation method for seeds and in vitro shoot tips of $B$. lenta in hopes of conserving available germplasm. Cryopreservation of mature seeds was successful with $24 \%$ of seeds germinating in the greenhouse and $12 \%$ of seeds germinating in vitro on medium supplemented with $10 \mu \mathrm{M}$ thidiazuron or 6-benzylaminopurine. Post-cryopreservation regrowth of in vitro shoot tips was achieved using a droplet-vitrification protocol after preculture in $0.3 \mathrm{M}$ sucrose for $24 \mathrm{~h}$ followed by osmoprotection in loading solution for $20 \mathrm{~min}$ and treatment with vitrification solution A3 composed of glycerol, sucrose, ethylene glycol and dimethylsulfoxide at $0^{\circ} \mathrm{C}$ for $60 \mathrm{~min}$. The highest plant regeneration (52\%) was obtained after unloading (rehydration) in medium with $0.8 \mathrm{M}$ sucrose for $30 \mathrm{~min}$. Differential scanning calorimetry analysis confirmed the absence of ice crystallization in the shoot tips during cooling and rewarming. This is the first 
23 report for successful cryopreservation of $B$. lenta, which will further promote initiatives for 24 conservation of North American biocultural diversity.

Keywords: Betula lenta, cryopreservation, droplet-vitrification, encapsulation-vitrification,

27 conservation, seeds, shoot tips

\section{Introduction}

33 Cherry birch or Sweet Birch, Betula lenta L., is an ecologically important tree species native to 34 North America (Fig. 1A) with purported medicinal uses amongst Native American and First 35 Nations peoples to treat fevers, colds and flues, or general malaise (Moerman 2009). Since 1967 36 the population for $B$. lenta in Canada has declined significantly (72\%) as a result of increased 37 pressures from urban development and shoreline erosion. To date it is estimated that only 18 38 trees remain in the Niagara region of Ontario, Canada (Zoladeski and Hayes 2013). As a result of 39 the above, B. lenta is designated as endangered, with N1 (national rank) and S1 (provincial rank) 40 designations in Canada (COSEWIC 2006).

Current strategies to conserve and recover this species in Canada include monitoring

42 (keeping track of trees and their health) and maintaining the current habitat (Zoladeski and Hayes 43 2013) as well as planting trees in arboretums. Recently an efficient protocol for in vitro 44 propagation of $B$. lenta was developed at the Gosling Research Institute for Plant Preservation 45 (GRIPP), University of Guelph (Canada) (Rathwell et al. 2016). However, all these options have 
46 limitations in terms of long-term conservation. Trees in the natural environment and arboretums

47 are susceptible to pests, diseases, and environmental changes, while in vitro collections are expensive to maintain and are prone to contamination (Benelli et al. 2013). Conventional methods for seed banking where seeds are stored in both cold $\left(-18^{\circ} \mathrm{C}\right.$ to $\left.4^{\circ} \mathrm{C}\right)$ and $\operatorname{dry}(3-5 \%$ moisture content, MC) environments are not efficient for Betula species, as seed germination can

51 decrease significantly over time under these conditions (Heit 1967; Seed Information Database

52 of the Royal Botanic Gardens Kew, SID 2015). Furthermore, there is currently scarce

53 information available with respect to the storage behavior of cherry birch seeds.

In order to further support conservation efforts, this study aimed to develop a protocol for cryopreservation in liquid nitrogen $\left(\mathrm{LN},-196^{\circ} \mathrm{C}\right)$ of $B$. lenta seed and in vitro shoot tips. Cryopreservation is a highly efficient method for long-term storage of living cells and tissues

57 (Pritchard and Nadarajan 2008). At cryogenic temperatures below $-130^{\circ} \mathrm{C}$, cell division and nearly all metabolic activities of cells cease, and samples can theoretically be preserved for hundreds of years while requiring limited space and maintenance compared to material grown in vitro or in the field (Benelli et al. 2013). The type of material (e.g. seeds, dormant buds, or shoot

61 buds), its moisture content, and the physiological status before cryopreservation are known to 62 significantly influence regrowth after cryopreservation (Sakai and Engelmann 2007). Seeds are 63 the preferred option for cryobanking native plant species, however, as is the case for B. lenta, 64 they are difficult to collect due to high annual variation in seed production. Cryopreservation of 65 vegetative plant tissues is challenging, primarily due to the high amount of water that can be converted into ice which in turn may cause irreversible cell damage during cooling and 67 rewarming. Reducing $\mathrm{MC}$ in the samples prior to cryopreservation as well as applying 68 cryoprotectant solutions can help minimize such damage (Volk and Walters 2006). The process 
of dehydration and cryoprotection may, however, require optimization for every new species in order to obtain regrowth (Sakai and Engelmann 2007).

Two methods were used for cryopreserving in vitro shoot tips in this study: (1) encapsulation-dehydration and (2) droplet-vitrification. Encapsulation of tissues in a sodiumalginate matrix followed by dehydration in air or in cryoprotectant solutions (Fabre and Dereuddre 1990; Paul et al. 2000) prior to cooling is preferable when operating with fragile and sensitive materials (Sakai and Engelmann 2007). In droplet-vitrification, shoot tips are dehydrated in highly concentrated cryoprotectant solutions (vitrification solutions, VS) and then cryopreserved in tiny drops of VS attached to aluminum foil strips to ensure high rates of cooling and rewarming (Panis et al. 2005; Teixeira et al. 2014). This method has proven effective for cryopreserving shoot tips of important agricultural crops such as potato, chrysanthemum, garlic, and banana (Panis et al. 2005; Kim et al. 2012), however, high toxicity of many VS may limit their application (Sakai and Engelmann 2007; Kim et al. 2009b). To date, vitrification and encapsulation-based methods have not been applied to B. lenta germplasm, however, they have been used for cryopreserving vegetative materials of trees and shrubs in several genera including Populus, Prunus, Quercus, Malus, Picea, and Olea (Benelli et al. 2013; Pritchard et al. 2014). The main objective of this study was to develop a protocol for cryopreservation of $B$. lenta using seed and in vitro shoot tips, thus allowing the use of this approach for the conservation of endangered Canadian cherry birch.

\section{Materials and Methods}

Cryopreservation of Seeds: Seeds were collected from mature cherry birch trees maintained in the University of Guelph Arboretum during the winters of 2012/2013 and 2013/2014, and were 
92 stored at $4^{\circ} \mathrm{C}$. Moisture content was measured by placing seeds in an oven at $100^{\circ} \mathrm{C}$ and

93 recording change in weight at various time intervals until a constant weight was achieved.

94 Moisture content was calculated using the formula:

$$
M C=\frac{\mathrm{fw}-\mathrm{dw}}{f w}
$$

95 where $\mathrm{MC}$ is the moisture content, and $f w$ and $d w$ are the weights of fresh and dried seeds, 96 respectively. MC was expressed in percentage. Measurement was performed in three technical 97 replications, each containing at least 30 seeds, and repeated twice.

To determine the impact of cryopreservation, seeds were sealed in $2 \mathrm{ml}$ cryovials (Nunc,

99 USA) and stored in LN for a minimum of one hour. Cryovials were then placed in a $40^{\circ} \mathrm{C}$ water 100 bath for 90 seconds to re-warm. Control and cryopreserved seeds were surface sterilized with $4 \%$ 101 commercial bleach (Clorox ${ }^{\circledR}$, The Clorox company; 5.4\% sodium hypochlorite) for one hour, 102 followed by $20 \%$ bleach for $15 \mathrm{~min}$, and rinsed with autoclaved deionized water four times, each 103 wash for $3 \mathrm{~min}$.

104 For germination, seeds were plated on semi-solid or liquid media of the same 105 composition. Standard medium (STM) consisted of DKW basal salts (Driver and Kuniyuki 106 1984), 3\% sucrose and vitamins (100 mg/l myo-inositol $+2 \mathrm{mg} / 1$ glycine $+1 \mathrm{mg} / 1$ nicotinic 107 acid), without growth regulators. The semi-solid medium was prepared with $2.2 \mathrm{~g} / 1$ phytagel 108 (Sigma-Aldrich, Canada). To improve germination, this standard medium was supplemented 109 with 6-benzylaminopurine (BA) (Phytotechnology, Shawnee Mission, Kansas, USA), or 110 thidiazuron (TDZ) (Caisson, Logan, Utah, USA) at 10.0 or $20.0 \mu \mathrm{M}$. All treatments were kept in 111 the dark at $24 \pm 2^{\circ} \mathrm{C}$. Seed germination was recorded at various intervals over 66 days. 112 Germination was determined by the presence of developed cotyledons and roots and expressed 
113 as percentage out of the number of seeds taken for the treatment. Three to five replications were 114 used for each treatment; each replication contained 4 seeds.

Alternatively, control and cryopreserved seeds were planted directly in Sunshine

116 professional growing medium (Sun Gro Horticulture Canada Ltd., Vancouver, Canada) and 117 germinated in the greenhouse $\left(24^{\circ} \mathrm{C}\right.$ for $16 \mathrm{~h}$ light and $20^{\circ} \mathrm{C}$ for $8 \mathrm{~h}$ darkness, light intensity 110 $\left.118 \mu \mathrm{molm}^{-2} \mathrm{~s}^{-1}\right)$. Germination was recorded at various intervals over 66 days. Both control and 119 cryopreservation treatments were performed in twelve replications, each replication consisting of 12030 seeds.

121

122 Cryopreservation of in Vitro Shoot Tips

In vitro stock plants of $B$. lenta were obtained from the GRIPP (University of Guelph, 124 Guelph) in vitro collection and maintained on shoot induction media (SIM) at $25 \pm 2{ }^{\circ} \mathrm{C}$ under a

125 16-h photoperiod at light intensity of $40 \mathrm{~mol} \mathrm{~m}^{-2} \mathrm{~s}^{-1}$ by periodic subcultures every 6 weeks 126 (Rathwell et al. 2016). SIM was composed of DKW basal salts (Driver and Kuniyuki 1984), 3\% 127 sucrose and vitamins (100 mg/l myo-inositol $+2 \mathrm{mg} / \mathrm{l}$ glycine $+1 \mathrm{mg} / \mathrm{l} \mathrm{nicotinic}$ acid) and was 128 supplemented with $5 \mu \mathrm{M}$ BA and $1 \mu \mathrm{M}$ gibberellic acid $\left(\mathrm{GA}_{3}\right)$. Shoot tips with an average size of $1291.5-2.0 \mathrm{~mm}$ were dissected from: i) 12-day-old nodal segments or ii) 60-day-old plants. 130 Explants were placed on SIM for $24 \mathrm{~h}$ to recover from stress caused by excision. These shoot tips 131 were cryopreserved using encapsulation-vitrification or droplet-vitrification methods.

\section{Encapsulation-vitrification}

For encapsulation, shoot tips were excised from 60-day-old plants and suspended in 3\%

134 Na-alginate (Sigma-Aldrich, Canada). Alginate droplets, each containing one explant, were 135 transferred into $100 \mathrm{mM} \mathrm{CaCl} 2$ solution using a wide mouth $10 \mathrm{ml}$ serological pipette $(\mathrm{Costar} \AA$, 
136 USA) and left for $20 \mathrm{~min}$ with gentle agitation to form beads ca. $4 \mathrm{~mm}$ in diameter (Fabre and 137 Dereuddre 1990; Fig. 1D). Beads were precultured in $0.3 \mathrm{M}$ sucrose solution for $24 \mathrm{~h}$ and then 138 transferred into loading solution (2.0 M glycerol + 0.4 M sucrose) (Nishizawa et al. 1993) for 20 139 min at room temperature. Afterwards, plant vitrification solution 3 (PVS3), composed of 50\% 140 glycerol and 50\% sucrose, w/v (Nishizawa et al. 1993) was applied to beads for 20, 40 or $60 \mathrm{~min}$ 141 at room temperature on a shaker $(90 \mathrm{rpm})$. For cryopreservation, beads were placed in $2 \mathrm{ml}$ 142 cryovials filled with $1 \mathrm{ml}$ fresh PVS3. Cryovials were sealed and quickly immersed in LN for 143 one hour then rewarmed in a $40^{\circ} \mathrm{C}$ waterbath for 2 min. Beads were transferred to unloading 144 solution containing $1.2 \mathrm{M}$ sucrose for $40 \mathrm{~min}$ then placed on SIM for regrowth. Further 145 treatments aimed at the optimization of this technique included: i) using shoot tips without 146 alginate beads as compared to shoot tips encapsulated in alginate beads; and ii) removing shoot 147 tips from beads after rewarming and unloading, before plating them on SIM. All materials were 148 cultured in darkness for the initial five days after rewarming and then moved to low light 149 conditions $\left(5 \pm 2 \mu\right.$ molm $\left.^{-2} \mathrm{~s}^{-1}\right)$. Shoot tips that remained green after 10 days were counted for 150 "survival". Shoot tips that developed into plantlets after 30 days were counted to assess 151 "regeneration". All treatments were performed with three independent replications, each 152 containing at least 10 shoot tips.

Droplet-vitrification

Experiments were performed using shoot tips excised from 12-day-old nodal segments, if 156 not stated otherwise. In the first experiment, the effect of different steps of the droplet157 vitrification protocol, named preculture, osmoprotection and dehydration in VS, on shoot tip 
158 159

160

161

162

163

164

165

166

167

168

169

170

171

172

173

174

175

176

177 individual drop of ice-cold A3 on strips of aluminum foil (Western Plastics, Canada) $(6 \times 30$

178

179

180

regrowth was evaluated without cryopreservation. To do this, shoot tips were collected after each step in a series of sequential treatments including:

i) preculture in $0.3 \mathrm{M}$ sucrose solution for $24 \mathrm{~h}$;

ii) preculture and osmoprotection in loading solution $(1.9 \mathrm{M}$ glycerol $+0.5 \mathrm{M}$ sucrose, LS) (Kim et al. 2009a) for $20 \mathrm{~min}$ at room temperature;

iii) preculture, osmoprotection and exposure to VS A3 (37.5\% glycerol, $22.5 \%$ sucrose, $15 \%$ ethylene glycol (EG), and 15\% dimethyl sulfoxide (DMSO), w/v, (Kim et al. 2009b) at $0^{\circ} \mathrm{C}$ for $60 \mathrm{~min}$;

iv) preculture, osmoprotection and exposure to PVS3 for $60 \mathrm{~min}$ at room temperature.

Shoot tips after treatments (i) and (ii) were directly transferred to SIM in $6 \mathrm{~cm}$ Petri dishes. Shoot tips after treatments (iii) and (iv) were transferred into $1.2 \mathrm{M}$ sucrose solution (unloading solution) and for $30 \mathrm{~min}$ on a shaker $(90 \mathrm{rpm})$ to remove cryoprotectants, then placed on SIM in $6 \mathrm{~cm}$ Petri dishes. Cultures were kept under low light $\left(5 \pm 2 \mu \mathrm{molm}^{-2} \mathrm{~s}^{-1}\right)$ for the initial five days then transferred to light intensity of $110 \mu \mathrm{mol} \mathrm{m} \mathrm{s}^{-1}$. Survival and regeneration were assessed as described above in the encapsulation-vitrification method.

In the second experiment, cryopreservation of shoot tips was performed by preculturing in $0.3 \mathrm{M}$ sucrose for $24 \mathrm{~h}$, then transferring to an osmoprotected solution in LS for $20 \mathrm{~min}$, followed by treatment in VS A3 at $0^{\circ} \mathrm{C}$ for $60 \mathrm{~min}$. After that, each shoot tip was placed in an mm) (Fig. 1E). Foil strips with shoot tips were quickly immersed in LN for at least one hour. For rewarming, the foil strips were plunged in preheated $\left(40 \pm 1^{\circ} \mathrm{C}\right) 1.2 \mathrm{M}$ sucrose solution for 30 seconds; after which an equivalent volume of unloading solution at room temperature was added. 
181 Foils were removed with forceps and shoot tips were kept in unloading solution for 30 min on a 182 shaker $(90 \mathrm{rpm})$, blotted dry on sterile filter paper and plated on SIM for regrowth. Control shoot 183 tips were treated equally except they were not immersed in LN.

Since regeneration of shoot tips cryopreserved by this protocol remained below $25 \%$, 185 different modifications of the protocol steps were further investigated:

Preculture. Shoot tips were precultured in $0.3 \mathrm{M}$ sucrose for $24 \mathrm{~h}$ (standard protocol) or 187 step-wise in sucrose solutions with progressively increasing concentrations $(0.3 \mathrm{M}$ for 1 day then $0.5 \mathrm{M}$ for $16 \mathrm{~h}$ followed by $0.7 \mathrm{M}$ for $4 \mathrm{~h}$ ).

Cold hardening of donor plants. Shoot tips were excised from in vitro plants that were cold hardened on media supplemented with 3 and $5 \%$ sucrose for 6 and 12 days at $5^{\circ} \mathrm{C}$ in darkness. the most effective combination of VS type and treatment, various durations of exposure to VS A3 and PVS3 were tested with and without cryopreservation. Shoot tips were precultured and loaded as in standard protocol, then exposed to VS A3 at $0^{\circ} \mathrm{C}$ for $0,5,10,20,40,60$, or 80 min, 196 or to PVS3 for 30 or $60 \mathrm{~min}$ at room temperature. kinetin in culture media were tested in order to stimulate plant regeneration from cryopreserved shoot tips. The following combinations of growth regulators have been tested: "GA 3 ": $1 \mu \mathrm{M}$ $\mathrm{GA}_{3}$; "BKG": $2.5 \mu \mathrm{M}$ BA $+2.5 \mu \mathrm{M}$ kinetin $+1 \mu \mathrm{M} \mathrm{GA}_{3}$; "BG": $5 \mu \mathrm{M}$ BA $+1 \mu \mathrm{M} \mathrm{GA}_{3}$; "ZG": $5 \mu \mathrm{M}$ zeatin $+1 \mu \mathrm{M} \mathrm{GA}_{3}$; “KG": $5 \mu \mathrm{M}$ kinetin $+1 \mu \mathrm{M} \mathrm{GA}_{3}$. 
204

205

206

207

208

209

210

211

212

213

214

215

216

217

218

219

220

221

222

223

224

225

226

concentration of unloading solution and/or duration of unloading step. In this experiment, shoot tips were excised from 60-day-old plants and only plant regeneration was measured. Treatments included: $\operatorname{Tr} 1$ : standard protocol, $\operatorname{Tr} 2$ : osmoprotection for $40 \mathrm{~min}$, $\operatorname{Tr} 3$ : unloading in $0.8 \mathrm{M}$ sucrose for $30 \mathrm{~min}$, Tr4: unloading in $0.8 \mathrm{M}$ sucrose for $15 \mathrm{~min}, \mathrm{Tr} 5$ : unloading in $1.2 \mathrm{M}$ sucrose for $15 \mathrm{~min}$.

All solutions used for preculture, cryoprotection, and unloading were prepared in MS basal medium with $\mathrm{MS}$ vitamins $(\mathrm{pH}$ 5.7), and sterilized by filtering through $0.2 \mu \mathrm{M}$ filters (Falcon, USA).

All experiments in droplet-vitrification method were performed with three independent replications, each containing at least 10 shoot tips. Survival and regeneration were assessed as described in encapsulation-vitrification method.

\section{Differential Scanning Calorimetry Analysis}

Phase transitions in shoot tips of cherry birch were investigated using a Differential Scanning Calorimeter (DSC) (DSC1, Mettler Toledo, Leicester, UK), calibrated with zinc $\left(422.81^{\circ} \mathrm{C}, 115.57 \mathrm{~J} \mathrm{~g}^{-1}\right)$ and indium $\left(156.85^{\circ} \mathrm{C}, 29.03 \mathrm{~J} \mathrm{~g}^{-1}\right)$ standards. Shoot tips were sealed in $40 \mu \mathrm{l}$ aluminum pans. Samples were placed in the DSC at $22^{\circ} \mathrm{C}$ and cooled at a rate of $-10^{\circ} \mathrm{C}$ $\min ^{-1}$ to $-80^{\circ} \mathrm{C}$, at which temperature the sample was held isothermally for 5 min before rewarming to $25^{\circ} \mathrm{C}$ at a rate of $10^{\circ} \mathrm{C} \mathrm{min}^{-1}$. Samples tested included i) control shoot tips without any treatment and ii) shoot tips precultured in $0.3 \mathrm{M}$ sucrose for $24 \mathrm{~h}$ and exposed to loading solution for $20 \mathrm{~min}$ followed by either PVS3 (30 or $60 \mathrm{~min})$ or $\mathrm{A} 3$ at $0^{\circ} \mathrm{C}(20,40,60$, or $80 \mathrm{~min})$. Each treatment was replicated three times. Thermograms were analyzed using STARe thermal analysis software (Mettler Toledo, Leicester, UK). 
227

228

229

230

231

232

233

234

235

236

237

238

239

240

241

242

243

244

245

246

247

248

249

\section{Statistical Analysis}

Data from experiments were fist tested for normality using the D'Agostino-Pearson normality test. Normally distributed data were compared using a one-way ANOVA followed by Duncan`s multiple range test (MRT) in cases where the model was significant. If the data were not normally distributed, Kruskal-Wallis test was applied followed by Dunn's multiple comparisons test. All statistical analyses were conducted using JMP for Mac and SAS University edition 3.4 (SAS Institute Inc. Cary, North Carolina, USA). Statistics are presented as means with standard errors, and different letters in figures indicate significant differences at $\alpha=0.05$.

\section{Results}

\section{Cryopreservation of Seeds}

The average seed MC before cryopreservation was $10.5 \%$. Seeds collected during the winter 2012/2013 completely lost viability and did not germinate after two years of storage at $4^{\circ} \mathrm{C}$. One-year-old seeds from the 2013/2014 collection remained viable: $33-50 \%$ of seeds germinated in vitro and $31 \%$ of seeds germinated in the greenhouse (Fig. 2C). Highest germination of control (non-cryopreserved) seeds in vitro (50\%) was recorded in semi-solid medium supplemented with $20 \mu \mathrm{M}$ TDZ, followed by medium without growth regulators (Fig. $2 \mathrm{~A}, \mathrm{LNC})$. After cryopreservation, in vitro germination above $10 \%$ was observed only for seeds cultured on semi-solid media supplemented with $10 \mu \mathrm{M}$ TDZ, or liquid media supplemented with $10 \mu \mathrm{M}$ BA (Fig. 2, LN). Germination of cryopreserved seeds in the greenhouse was ca. $10 \%$ lower than for non-cryopreserved seeds (Fig. 2C). All seedlings that emerged from control and cryopreserved seeds developed into normal plants (Fig. 1B, C). 

260 beads.

\section{Cryopreservation of in Vitro Shoot Tips}

Isolated shoot tips that were placed on SIM without any treatment showed 100\% survival and shoot development (regeneration).

Encapsulation-vitrification. Over $80 \%$ survival was recorded prior to cryopreservation for shoot tips following all steps of the encapsulation-vitrification protocol. However, regeneration of plantlets from the encapsulated shoot tips was very poor (below 5\%). By contrast, $60 \%$ regeneration was observed for shoot tips that were manually removed from beads before placing them on culture medium for regrowth. After cryopreservation, shoot tips remained green for 10-15 days but were unable to develop shoots. No regeneration of cryopreserved shoot tips was recorded in any treatment including those when the explants were removed from the

Droplet-vitrification. More than $95 \%$ shoot tips survived after the two initial steps of the protocol, i.e. preculture and osmoprotection (Fig. 3). Meanwhile, regeneration was reduced to 92 and $88 \%$ after preculture and osmoprotection, respectively (Fig. 3). Both survival and regeneration sharply decreased after applying VS A3 or PVS3 (Fig. 3). The adverse effect of VS exposure was highly significant $(\mathrm{P}<0.0001)$ on regeneration which dropped down to $27 \%$ and 16\% after 60 min treatment with PVS3 and VS A3, respectively (Fig. 3). When shoot tips were exposed to VS A3 and PVS3 for various durations, no significant differences in survival and regeneration were observed between treatments without cryopreservation, mostly due to high variations between replications within each treatment (Fig. 4, LNC). After cryopreservation, treatment with A3 for 5 and 10 min resulted in survival of over $35 \%$, mostly due to callus formation as no plant regeneration was observed. The highest plant regeneration of $13 \%$ was 
272 obtained when shoot tips were treated with VS A3 for $80 \mathrm{~min}$, and with PVS3 for 60 min (Fig. 4,

273 LN), however the differences between the two solutions were not significant.

Shoot tips excised from cold hardened plants did not show any improvement in regrowth

275 after cryopreservation. Similarly, no beneficial effect on regrowth was observed when shoot tips

276 were precultured with step-wise increasing sucrose concentration (data not shown). Regeneration

277 of non-cryopreserved shoot tips was significantly $(\mathrm{P}<0.0082)$ higher on media supplemented

278 with $\mathrm{GA}_{3}$ alone without cytokinins (Fig. 5). Survival of cryopreserved shoot tips was higher on

279 media supplemented with $\mathrm{GA}_{3}$ alone or in combination with BA compared to media with kinetin

280 or zeatin. However, there was no significant difference in plant regeneration between

281 cryopreserved shoot tips cultured on different media (Fig. 5).

The highest regeneration of 52\% after cryopreservation was achieved when sucrose

284 the duration of unloading step from $30 \mathrm{~min}$ to $15 \mathrm{~min}(\operatorname{Trs} 4$ and 5$)$ significantly $(\mathrm{P}<0.0003)$ reduced regeneration while increasing osmoprotection step by $20 \mathrm{~min}(\operatorname{Tr} 2)$ showed no effect.

\section{Differential Scanning Calorimetry Analysis}

Thermograms were interpreted for critical cryopreservation parameters such as

289 crystallization, melt onset temperatures, and enthalpy of crystallization and melting. Exothermal 290 and endothermal peaks indicating, respectively, ice crystallization during cooling and ice 291 melting during rewarming were observed in shoot tips without any treatment (Fig. 7, Control) in 292 all replicates. By contrast, no crystallization or melting events could be detected if shoot tips 293 were preliminary treated with vitrification solutions A3 or PVS3 for all time periods tested (Fig. 
294 7). These studies provide indirect evidence of the absence of ice in shoot tips cryoprotected 295 before cryopreservation.

Plant development and initiation of cherry birch collection in a cryobank following the protocol developed earlier (Rathwell et al. 2016) to obtain healthy looking young 302 plants with roots.

The cryopreservation method developed in this study was used to initiate the long-term storage collection of $B$. lenta germplasm at the GRIPP cryobank by cryopreserving 200 shoot tips. 30 additional shoot tips were simultaneously cryopreserved and rewarmed after one hour as an inner control; these shoot tips showed 50\% plant regeneration (data not presented).

\section{Discussion}

Cryopreservation of endangered tree species can be achieved by using seeds, pollen, winter buds and in vitro cultured materials, however all of these propagules have their own limitations. Storing seeds is an efficient and practical approach as a large diversity of genotypes

312 can be stored using minimal space (Pritchard et al. 2014). Seed cryostorage in $\mathrm{LN}\left(-196^{\circ} \mathrm{C}\right)$ or in 313 its vapor phase $\left(-160\right.$ to $\left.-195^{\circ} \mathrm{C}\right)$ has been successfully applied to conserve wild plant species at 314 risk (e.g. Pence 1991; Kholina and Voronkova 2008; Chmieraz 2010b; Popova et al. 2013; 315 Michalak et al. 2015). Seeds of B. lenta are listed as orthodox in the Seed Information Database 316 of Kew Botanical Garden (SID 2015). The same database referred to Joseph (1929) for the 
317 statement that $77 \%$ of $B$. lenta seeds were able to germinate after 1.5 years of hermetic storage at 318 room temperature with 7.4\% MC. According to Brinkman (1974), seeds of Betula species can be 319 stored at room temperature with 1\% MC. The Canadian Forestry Service (Wang 1974) reported 320 that $B$. lenta seeds tolerated desiccation to $1 \% \mathrm{MC}$ and recommended hermetic storage at 321 temperatures of $3^{\circ} \mathrm{C}$ to $-25^{\circ} \mathrm{C}$ with $1-3 \% \mathrm{MC}$ for their long-term conservation. Supporting the 322 data on orthodox behavior of birch seeds, Chmielarz (2010a) reported that seeds of silver birch 323 (Betula pendula Roth.) tolerated desiccation over silicagel to $0.02 \mathrm{~g} \mathrm{~g}^{-1}$, with $77 \%$ of seeds 324 germinating after 14 days of sowing. Chmielarz (2010a) also referred to other studies where 325 seeds of Betula species with $8-10 \% \mathrm{MC}$ could be stored at $-25^{\circ} \mathrm{C}$ for $10-12$ years (Heit 1967 ; 326 Wang 1974). In our study, mature seeds of cherry birch completely lost their viability after two 327 years of storage at $4^{\circ} \mathrm{C}$ with $10.5 \% \mathrm{MC}$, while one-year-old seeds showed $30-32 \%$ germination 328 in the greenhouse. In vitro germination rates ranged from 0 to $50 \%$ depending on the medium 329 used. Relatively low germination of cherry birch seeds in this study may have resulted from 330 storage conditions at $4^{\circ} \mathrm{C}$ or may be related to seed dormancy which has been previously 331 reported for Betula species (Chmielarz 2010a; De Atrip and O`Reilly 2006). Cryopreserving seeds within a range of safe $\mathrm{MC}$ is crucial for their survival after cryopreservation (Pritchard et al. 2014). While a safe MC window varies among species, it is 334 generally accepted that orthodox seeds with a MC below 13\% are sufficiently dry to be 335 cryopreserved without any reduction in germination rates being seen (Pritchard and Nadarajan 336 2008). For dormant seeds of closely related species such as B. pendula, the safe range of MC for 337 cryopreservation was found to be between 2.0 and 18.7\% (Chmielarz 2010a). In comparison, 338 safe MC for cryopreservation of orthodox seeds was $7.4-19.4 \%$ for Fraxinus excelsior L. 339 (Chmielarz 2009) and 2.9 - 17.4\% for Ulmus glabra Huds (Chmielarz 2010b). Thus, it is likely 
340 that B. lenta seeds cryopreserved at $10.5 \% \mathrm{MC}$ should be within their safe MC range. However,

341 this does not guarantee that their germination will be fully retained after cryogenic exposure and

342 rewarming as other factors such as cooling and rewarming velocity, presence of the pericarp and

343 seed provenance may influence seed viability (Kholina and Voronkova 2008; Popova et al. 2013,

344 2016). Since there is limited information in the literature about the physiology of $B$. lenta seeds,

345 further investigation is required to reveal factors that caused low germination after 346 cryopreservation. Apart from lower germination, cryopreservation had no negative effect on seed

347 development. The plantlets raised from cryopreserved seeds both in vitro and in a greenhouse 348 appeared strong and healthy without any abnormalities or delay in growth. Thus, the 349 cryopreservation protocol is expected to provide germination of seeds, which are physiologically 350 competent. In the future, the simplicity of the protocol would allow testing of seeds collected 351 from various trees at various environmental conditions over years to select best material for 352 cryopreservation.

353 Cryopreservation of in vitro shoot tips is a valuable option for conservation of tree 354 genetic resources (Ryynänen and Aronen 2005). Various methods such as vitrification, 355 encapsulation-dehydration, and encapsulation-vitrification have been proven effective for 356 cryopreserving shoot tips of American elm (Uchendu et al. 2013), white poplar (Lambardi et al. 357 2000), silver birch (Ryynänen and Aronen 2005) and others (Häggman et al. 2008 and Benelli et 358 al. 2013). In this study encapsulation-vitrification did not work, and the cryopreserved shoot tips 359 died within two weeks after rewarming. One of the reasons could be a detrimental effect of the 360 alginate matrix that suppressed the growth of regenerating plantlets out of the beads or 361 insufficient dehydration of alginate-coated shoot tips. 
Successful cryopreservation was achieved using a modified droplet-vitrification protocol.

363 As with almost any vegetative material, shoot tips of in vitro cultured plants experience severe stress during the cryopreservation process which may arise due to a combination of osmotic, mechanical, temperature, chemical, oxidative, and other detrimental events (Sakai and 366 Engelmann 2007). This stress is intensified by toxic effects of some cryoprotectant chemicals

367 (Volk and Walters 2006). The composition of a cryoprotectant solution and the duration of 368 exposure are the most critical factors in plant cryopreservation (Sakai and Engelmann 2007). The results of the present study showed high sensitivity of cherry birch shoot tips to the toxic effects of both PVS3 and VS A3 solutions as a sharp drop of both survival and regeneration percentage

371 after 60 min treatment (Fig. 3). The most prominent adverse effect was observed with plant 372 regeneration, which dropped from $100 \%$ for the untreated shoot tips to $15 \%$ after 20 min of 373 treatment with A3 solution and without cryopreservation (Fig. 4). The highest regeneration of 374 cryopreserved shoot tips was observed following treatment with A3 solution for 80 min and with 375 PVS3 solution for $30 \mathrm{~min}$ (Fig. 4). In comparison, the optimum duration of exposure to another 376 well-known four-component vitrification solution PVS2 was 60 min at $0^{\circ} \mathrm{C}$ for white poplar 377 (Lambardi et al. 2000), 120 min at $0^{\circ} \mathrm{C}$ for silver birch (Ryynänen and Aronen 2005) and 105 $378 \min$ at $25^{\circ} \mathrm{C}$ for cherry shoot tips (Niino et al. 1997). Recently, Vujović et al. (2015) reported 379 cryopreservation of plum shoot tips using two variations of the aluminum cryo-plate method and 380 A3 solution for cryoprotection with average regrowth between $58-78 \%$ in cherry plum and 28 $38148 \%$ in plum cultivar "Požegača". The results shown in Figs 3 and 4, and the absence of ice 382 crystallization during cryopreservation process confirmed by DSC (Fig. 7) suggest that low 383 regeneration after cryopreservation was likely caused by explant sensitivity to dehydration stress 384 and/or toxicity of VS rather than ice crystallization-induced damage. In other words, the protocol 
385 provided sufficient cryoprotection, but the explants could not tolerate the treatment due to their

386 sensitivity. The two common ways to solve this situation are to increase desiccation tolerance of

387 the initial plant material and to optimize the protocol to help the explants survive through severe

388 dehydration and rehydration stresses.

389

390

391

392

393

394

395

396

397

398

399

400

401

402

403

404

405

406

407

Cold-hardening at low positive temperatures and preculture with elevated sucrose concentrations is often used for plant materials in order to induce their desiccation and chilling tolerance, help mitigate osmotic stress, and reduce injury during cryopreservation (Sakai and Engelmann 2007). In the present study, however, such treatments did not result in any significant improvement towards regeneration. Also, no beneficial effect was obtained by removal or changing the type of cytokinins in the regrowth media (Fig. 5). The media used was previously optimized for cherry birch (Rathwell et al. 2016) therefore we did not test other combinations and concentrations of growth regulators.

The results of protocol modification (Fig. 6) demonstrate the importance of individual steps of the cryopreservation procedure for plant regrowth. Improvement in regeneration was observed after reducing sucrose concentration $(0.8 \mathrm{M})$ in the unloading solution and its duration. During unloading, cryoprotectants are removed from the shoot tips, and the kinetics of this process is affected by shoot tips size and the composition of VS. For example, concentration of DMSO in PVS2-pretreated garlic shoot tips decreased sharply from 70 to $60 \mathrm{mg} / \mathrm{g}$ fresh weight within the first $10 \mathrm{~min}$ of unloading followed by further slow decrease to $56 \mathrm{mg} / \mathrm{g}$ fresh weight during the next 50 min (Kim et al. 2004). By contrast, the glycerol concentration in PVS3treated shoot tips decreased slowly and steadily during 90 min of unloading (Kim et al. 2005). It is likely that for shoot tips of cherry birch, which are highly sensitive to VS, it is important to remove the components of VS or significantly reduce their concentration before placing the 
408 explants on medium for regrowth. Reducing the concentration of sucrose in unloading solution 409 may speed up removal of toxic cryoprotectant chemical. Osmotic potential of unloading solution 410 may also influence regeneration of shoot tips by controlling the rehydration process. It has been 411 shown that $\mathrm{MC}$ of shoot tips may increase by $20 \%$ during the first 10 min of unloading (Kim et 412 al. 2005). Thus it is essential to find the balance between the potentially beneficial and hazardous 413 effects at every step of the procedure, including rehydration. Based on these preliminary 414 findings, further optimization of the protocol can be done in the future to improve post415 cryopreservation performance of cherry birch shoot tips. The plants developed from 416 cryopreserved shoot tips grew well, looked healthy and could be further multiplied using the 417 method of in vitro propagation developed earlier (Fig. 1G) to produce large number of plants for 418 replenishing habitats.

In conclusion, this is the first report on successful cryopreservation of cherry birch, an

420 endangered species in Canada. Using cryopreserved seeds or shoot tips, vigorous and healthy

421 plants were obtained in vitro, and used further for subsequent propagation and acclimatization in

422 the greenhouse. A long-term storage collection for B. lenta has been initiated by placing the first 423200 shoot tips of cherry birch in the GRIPP cryobank at the University of Guelph (Guelph, 424 Canada). These results also open the door for more detailed studies on $B$. lenta seed storage 425 behavior and the application of cryopreservation protocols in conservation strategies, and may 426 provide a model for conserving other tree species of concern. Furthermore, this study also 427 demonstrates the potential in vitro culture technologies for species recovery and a long-term 428 conservation of Canadian plant biodiversity including the species with biocultural, medicinal, 429 and agricultural significance. 


\section{Acknowledgements}

433 This research was supported by the grants from the Gosling Foundation, Guelph, Canada to the 434 Gosling Research Institute for Plant Preservation (GRIPP). 


\section{References}

Benelli, C., de Carlo, A., and Engelmann, F. 2013. Recent advances in the cryopreservation of shoot-derived germplasm of economically important fruit trees of Actinidia, Diospyros, Malus, Olea, Prunus, Pyrus and Vitis. Biotechnol. Adv. 31(2):175-185. doi: 10.1016/j.biotechadv.2012.09.004

Brinkman, K.A. 1974. Betula L. In Seeds of Woody Plants in the United States. Agriculture Handbook No 450. Forest Service, USDA, Washington DC. pp. 252-257.

Chmielarz, P. 2010a. Cryopreservation of conditionally dormant orthodox seeds of Betula pendula. Acta Physiol. Plant. 32(3):591-596. doi: 10.1007/s11738-009-0437-6

Chmielarz, P. 2009. Cryopreservation of dormant European ash (Fraxinus excelsior) orthodox seeds. Tree Physiol. 29(10):1279-1285. doi: 10.1093/treephys/tpp064

Chmielarz, P. 2010b. Cryopreservation of the non-dormant orthodox seeds of Ulmus glabra. Acta Biol. Hung. 61(2):224-233. doi: 10.1556/ABiol.61.2010.2.10.

COSEWIC. 2006. COSEWIC Assessment and Status Report on the Cherry Birch (Betula lenta) in Canada [online]. Available from www.sararegistry.gc.ca/status/status_e.cfm [accessed 11 April 2016].

De Atrip, N., and O`Reilly, C. 2006. The response of prechilled alder and birch seeds to drying, freezing, and storage. Can. J. For. Res. 36(3):749-760. doi: 10.1139/x05-268.

Driver, J. A., and Kuniyuki, A.H. 1984. In vitro propagation of paradox walnut rootstock. Hortsci. 19(4): 507-509. 
Fabre, J., and Dereuddre, J. 1990. Encapsulation-dehydration: a new approach to cryopreservation of Solanum shoot tips. CryoLett. 11: 413-426.

Häggman H, Rusanen M, and Jokipii S. 2008. Cryopreservation of in vitro tissues of deciduous forest trees. In Plant cryopreservation: a practical guide. Edited by B.M. Reed. Springer, Berlin. pp. 365-386.

Heit, C. 1967. Propagation from seed: Storage of deciduous tree and shrub seeds. Am. Nurseryman. 126(10): 12-13, 86-94.

Joseph, H.C. 1929. Germination and vitality of birch seeds. Bot. Gazette 87(1):127-151. Stable URL: http://www.jstor.org/stable/2470925

Kholina, A.B., and Voronkova, N.M. 2008. Conserving the gene pool of Far Eastern plants by means of seed cryopreservation. Biol. Bull. 35(3): 262-269. doi: $10.1134 / \mathrm{S} 1062359008030060$

Kim, H.H., Lee, Y.G., Park, S.U., Lee, S.C., Baek, H.J., Cho, E.G., and Engelmann, F. 2009a. Development of alternative loading solutions in droplet-vitrification procedures. CryoLett. 30(4):291-299. http://www.cryoletters.org/Abstracts/vol_30_4_2009.htm\#291 [accessed 11 April 2016].

Kim, H.H., Lee, Y.G., Shin, D.J., Ko, H.C., Gwag, J.G., Cho, E.G., et al. 2009b. Development of alternative plant vitrification solutions in droplet-vitrification procedures. CryoLett. 30(5): 320-334. http://www.cryoletters.org/Abstracts/vol_30_5_2009.htm\#320 [accessed 11 April 2016].

Kim, H.H., Popova, E., Shin, D.J., Yi, J.Y., Kim, C.H., Lee, J.S., et al. 2012. Cryobanking of Korean Allium germplasm collections: results from a 10 year experience. CryoLett. 33(1): 
45-57. http://www.cryoletters.org/Abstracts/vol_33_1_2012.htm\#045 [accessed 11 April 2016].

Kim, H.H., Kim, J.B., Baek, H.J., Cho, E.G., Chae, Y.A., and Engelmann, F. 2004. Evolution of DMSO concentration in garlic shoot tips during a vitrification procedure. CryoLett. 25(2): 91-100. http://www.cryoletters.org/Abstracts/vol_25_2_2004.htm [accessed 11 April 2016].

Kim, J.B., Kim, H.H., Baek, H.J., Cho, E.G., Kim, Y.H., and Engelmann F. 2005. Changes in sucrose and glycerol content in garlic shoot tips during freezing using PVS3 solution. CryoLett. 26(2): 103-112. http://www.cryoletters.org/Abstracts/vol_26_2_2005.htm [accessed 11 April 2016].

Lambardi, M., Fabbri, A., and Caccavale, A. 2000. Cryopreservation of white poplar (Populus alba L.) by vitrification of in vitro-grown shoot tips. Plant Cell Rep. 19(3): 213-218. doi: $10.1007 / \mathrm{s} 002990050001$

Michalak, M., Plitta, B.P., Tylkowski, T., Chmielarz, P. and Suszka, J. 2015. Desiccation tolerance and cryopreservation of seeds of black poplar (Populus nigra L.), a disappearing tree species in Europe. Eur. J. For. Res. 134(1): 53-60. doi: 10.1007/s002990050001

Moerman, D.E. 2009. Native American Ethnobotany. Timber Press, Inc, Portland, Oregon. ISSBN: 0881924539.

Niino, T., Tashiro, K., Suzuki, M., Ohuchi, S., Magoshi, J., and Akihama, T. 1997. Cryopreservation of in vitro grown shoot tips of cherry and sweet cherry by one-step vitrification. Sci. Hortic. (Amsterdam). 70(2-3):155-163. doi:10.1016/S03044238(97)00062-9 
Nishizawa, S., Sakai, A., Amano, A.Y., and Matsuzawa, T. 1993. Cryopreservation of asparagus (Asparagus officinalis L.) embryogenic suspension cells and subsequent plant regeneration by vitrification. Plant Sci. 91(1):67-73. doi:10.1016/0168-9452(93)90189-7

Panis, B., Piette, B., and Swennen, R. 2005. Droplet vitrification of apical meristems: a cryopreservation protocol applicable to all Musaceae. Plant Sci. 168(1): 45-55. doi:10.1016/j.plantsci.2004.07.022

Paul, H., Daigny, G., and Sangwan-Norreel, B.S. 2000. Cryopreservation of apple (Malus $\times$ domestica Borkh.) shoot tips following encapsulation-dehydration or encapsulationvitrification. Plant Cell Rep. 19(8): 768-774. doi: 10.1007/s002990000195

Pence, V.C. 1991. Cryopreservation of Seeds of Ohio Native Plants and Related Species. Seed Sci. Technol. 19: 235-251.

Popova, E.V., Kim, D.H., Han, S.H., Moltchanova, E., Pritchard, H.W., and Hong, Y.P. 2013. Systematic overestimation of Salicaceae seed survival using radicle emergence in response to drying and storage: implications for ex situ seed banking. Acta Physiol. Plant. 35(10): 3015-3025. doi: 10.1007/s002990000195

Popova, E., Moltchanova, E., Han, S.H., Saxena, P., and Kim, D.H. 2016. Cryopreservation of Prunus padus L. seeds: emphasising the significance of Bayesian methods for data analysis. Can. J. For. Res. 2016. Accepted for publication. doi: 10.1139/cjfr-2016-0020

Pritchard, H.W., and Nadarajan, J. 2008. Cryopreservation of orthodox (desiccation tolerant) seeds. In Plant cryopreservation: a practical guide. Edited by B.M. Reed. Springer, Berlin. pp. $485-501$. 
Pritchard, H. W., Moat, J. F., Ferraz, J. B.S., Marks, T. R., Camargo, J. L. C., Nadarajan, J., and Ferraz, I.D.K. 2014. Innovative approaches to the preservation of forest trees. For. Ecol. Manage. 333(1): 88-98. doi:10.1016/j.foreco.2014.08.012

Rathwell, R., Mukund, S.R., Jones, A.M.P. and Saxena, P.K. 2016. In vitro propagation of cherry birch (Betula lenta L.). Can. J. Plant Sci. Accepted for publication. doi: 10.1139/CJPS-2015-0331

Ryynänen, L.A., and Aronen, T. 2005. Vitrification, a complementary cryopreservation method for Betula pendula Roth. Cryobiol. 51(2): 208-219. doi:10.1016/j.cryobiol.2005.07.006

Sakai, A. and Engelmann, F. 2007. Vitrification, encapsulation-vitrification and droplet$\begin{array}{lllll}\text { vitrification: } & \text { a } & \text { review. } & \text { CryoLett. } & \mathbf{2 8}(3):\end{array}$ http://www.cryoletters.org/Abstracts/vol_28_3_2007.htm [accessed 11 April 2016].

SID. 2015. Royal Botanic Gardens Kew Seed Information Database.Version 7.1. Available from: http://data.kew.org/sid/ [accessed 11 April 2016].

Teixeira, A.S., Gonzalez-Benito, M.E. and Molina-Garcia, A.D. 2015. Measurement of cooling and warming rates in vitrification-based plant cryopreservation protocols. Biotechnol. Prog. 30(5): 1177-1184. doi: 10.1002/btpr.1938

Uchendu, E.E., Shukla, M.R., Reed, B.M., and Saxena, P.K. 2013. Melatonin enhances the recovery of cryopreserved shoot tips of American elm (Ulmus americana L.). J. Pineal Res. 55(4): 435-442. doi: 10.1111/jpi.12094

Volk, G.M., and Walters, C. 2006. Plant vitrification solution 2 lowers water content and alters freezing behavior in shoot tips during cryoprotection. Cryobiol. 52(1): 48-61. doi:10.1016/j.cryobiol.2005.09.004 
Vujović, T., Chatelet, P., Ružić, Đ., and Engelmann, F. 2015. Cryopreservation of Prunus spp. using aluminium cryo-plates. Sci. Hort. 195: 173-182. doi:10.1016/j.scienta.2015.09.016

Wang, B.S.P. 1974. Tree-seed storage. Canadian Forestry Service Publication No 1335. Department of the Environment, Ottawa. Available from http://cfs.nrcan.gc.ca/pubwarehouse/pdfs/31917.pdf [accessed 11 April 2016].

Zoladeski, C. and Hayes, K. 2013. Recovery strategy for the cherry birch (Betula lenta) in Ontario. Available from http://files.ontario.ca/environment-and-energy/species-atrisk/stdprod_075574.pdf [accessed 11 April 2016]. 


\section{Figure Captions}

Fig. 1. A -30-years-old Betula lenta tree in the Arboretum of the University of Guelph (Ontario, Canada); B, C - germination of cryopreserved seeds in vitro and in the greenhouse, respectively; D - shoot tips encapsulated in alginate beads; E - shoot tips in drops of A3 solution on aluminium foil strip before immersion into liquid nitrogen, bar $=5 \mathrm{~mm} ; \mathbf{F}-$ regrowth of the shoot tip cryopreserved by droplet-vitrification method; G - In vitro plants developed from the cryopreserved shoot tips.

Fig. 2. Germination of control (LNC) and cryopreserved (LN) seeds. A - semi-solid media; B liquid media. C - seeds sown in the greenhouse. BA - benzylaminopurine, TDZ - thidiazuron. Numbers in baskets show the concentrations (in $\mu \mathrm{M}$ ) of BA or TDZ in the medium. Basal basal media without growth regulators. No germination was observed on media supplemented with $20 \mu \mathrm{M}$ BA in any treatment; this media is not shown for simplicity.

Fig. 3. Effect of different stages of the droplet-vitrification protocol on survival and regeneration of shoot tips (without cryopreservation). Con - control (untreated) shoot tips. PC - preculture with $0.3 \mathrm{M}$ sucrose for $24 \mathrm{~h}, \mathrm{PC}+\mathrm{LS}$ - preculture followed by loading solution for $20 \mathrm{~min}$ (osmoprotection), $\mathrm{PC}+\mathrm{LS}+\mathrm{A} 3$ and $\mathrm{PC}+\mathrm{LS}+\mathrm{PVS} 3$ - shoot tips after preculture and osmoprotection were treated for 60 min with vitrification solution $\mathrm{A} 3$ at $0^{\circ} \mathrm{C}$ or with PVS3 at room temperature, respectively. Values followed by different letters are significantly different based on Duncan MRT (Survival) or Dunn's multiple comparisons test (Regeneration) at $\alpha=$ 0.05 . 
Fig. 4. Effect of treatment duration with A3 and PVS3 cryoprotectant solutions on shoot tip survival and regeneration before (LNC) and after (LN) cryopreservation using dropletvitrification method. VS A3 was applied at $0^{\circ} \mathrm{C}$. Values followed by different letters are significantly different based on Dunn's multiple comparisons test at $\alpha=0.05$.

Fig. 5. Effect of combinations of various growth regulators in the regrowth media on survival and regeneration of shoot tips after treatment with $\mathrm{VS} \mathrm{A} 3$ at $0^{\circ} \mathrm{C}$ for $60 \mathrm{~min}$ (LNC) and cryopreservation (LN).

The following combinations of growth regulators have been tested: "GA,": $1 \mu \mathrm{M} \mathrm{GA}_{3}$; "BKG": $2.5 \mu \mathrm{M}$ BA + $2.5 \mu \mathrm{M}$ kinetin $+1 \mu \mathrm{M} \mathrm{GA}_{3}$; "BG": $5 \mu \mathrm{M}$ BA $+1 \mu \mathrm{M} \mathrm{GA}_{3}$; "ZG": $5 \mu \mathrm{M}$ zeatin $+1 \mu \mathrm{M} \mathrm{GA}_{3}$; "KG": $5 \mu \mathrm{M}$ kinetin $+1 \mu \mathrm{M} \mathrm{GA}_{3}$. Asterisk indicate the data sets where the effect of different media was significant $(\mathrm{P}<0.0082)$. Values followed by different letters are significantly different based on Duncan MRT at $\alpha=0.05$.

Fig. 6. Effect of modifications in osmoprotection and unloading steps on the regeneration of cryopreserved shoot tips. See Materials and Methods for the description of treatments. Values followed by different letters are significantly different based on Duncan MRT at $\alpha=0.05$.

Fig. 7. DSC thermograms of shoot tips without any treatment (Control) and after treatment with VS A3 and PVS3 for indicated durations. 


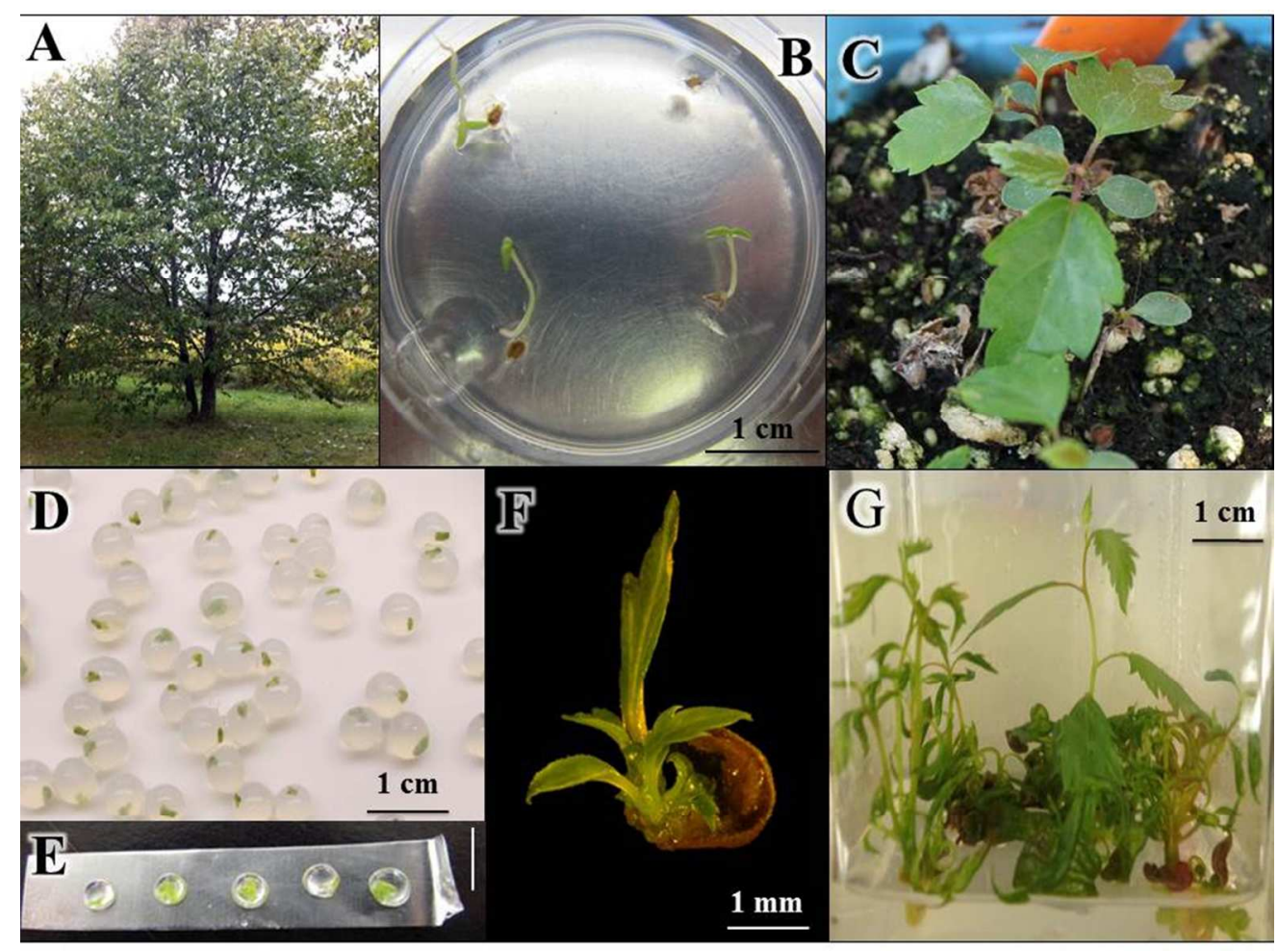

Fig. 1.

$254 \times 190 \mathrm{~mm}(96 \times 96$ DPI) 

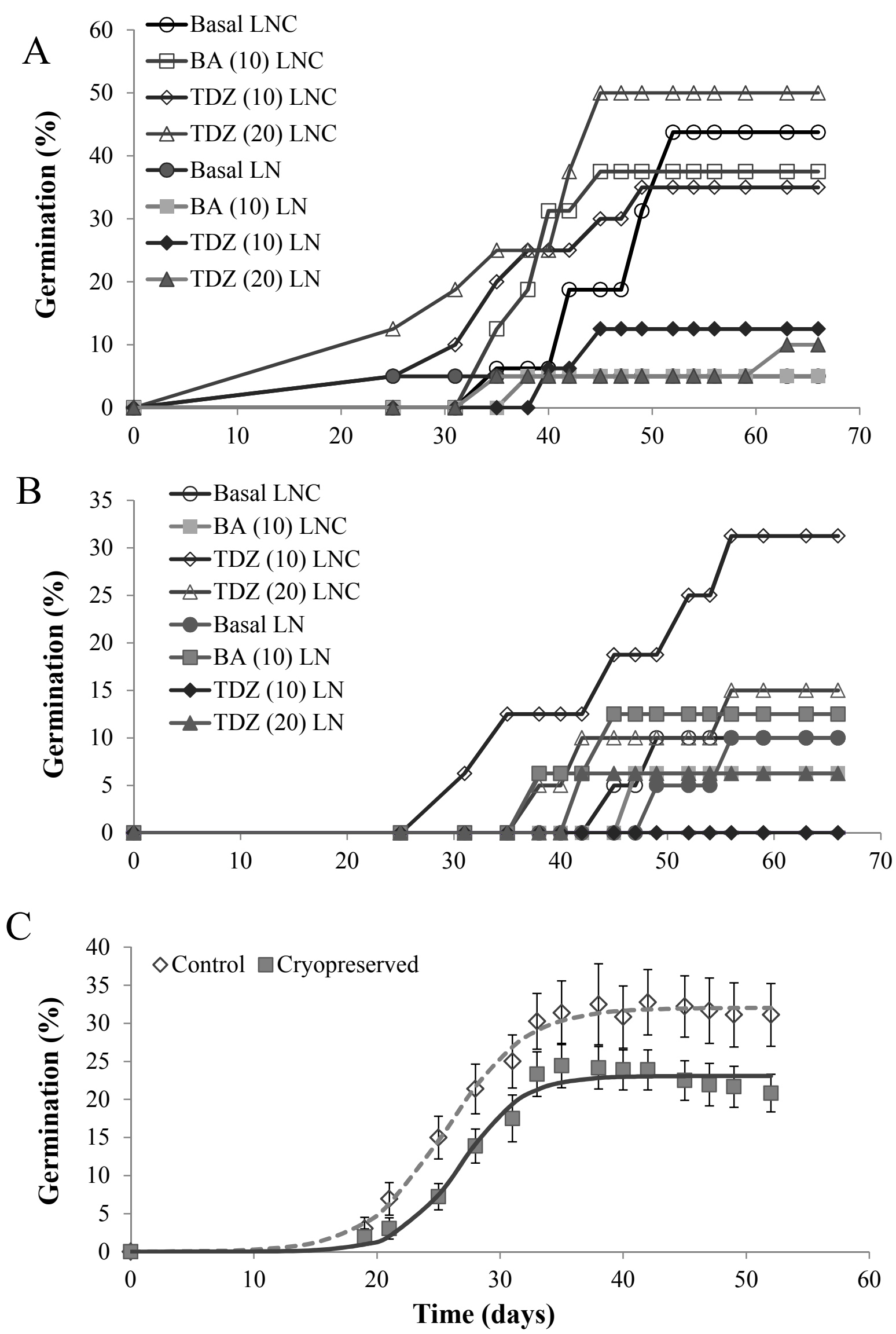

Fig. 2 

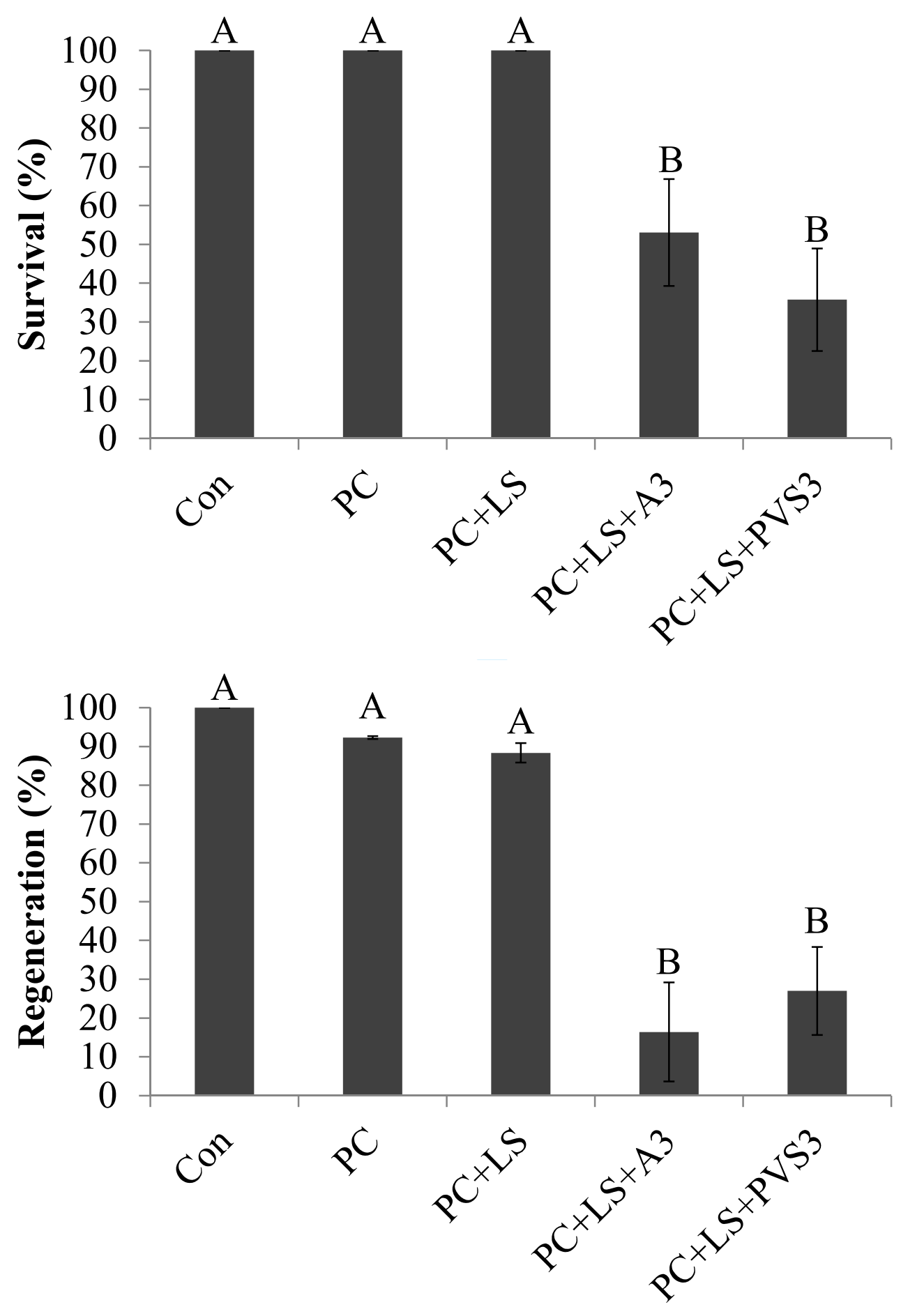

Fig. 3 

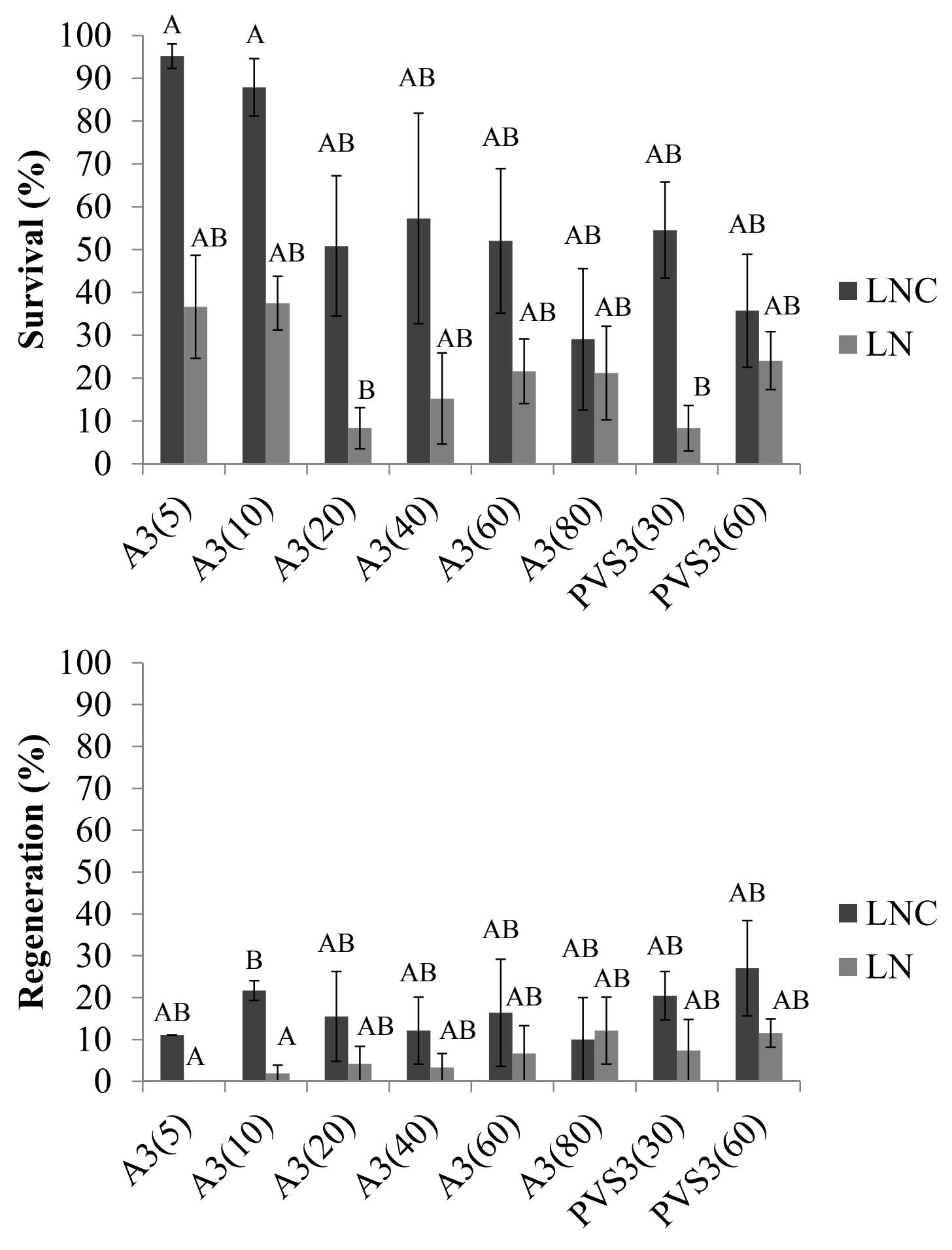

Cryoprotectant solution

(duration of treatment, min)

Fig. 4 


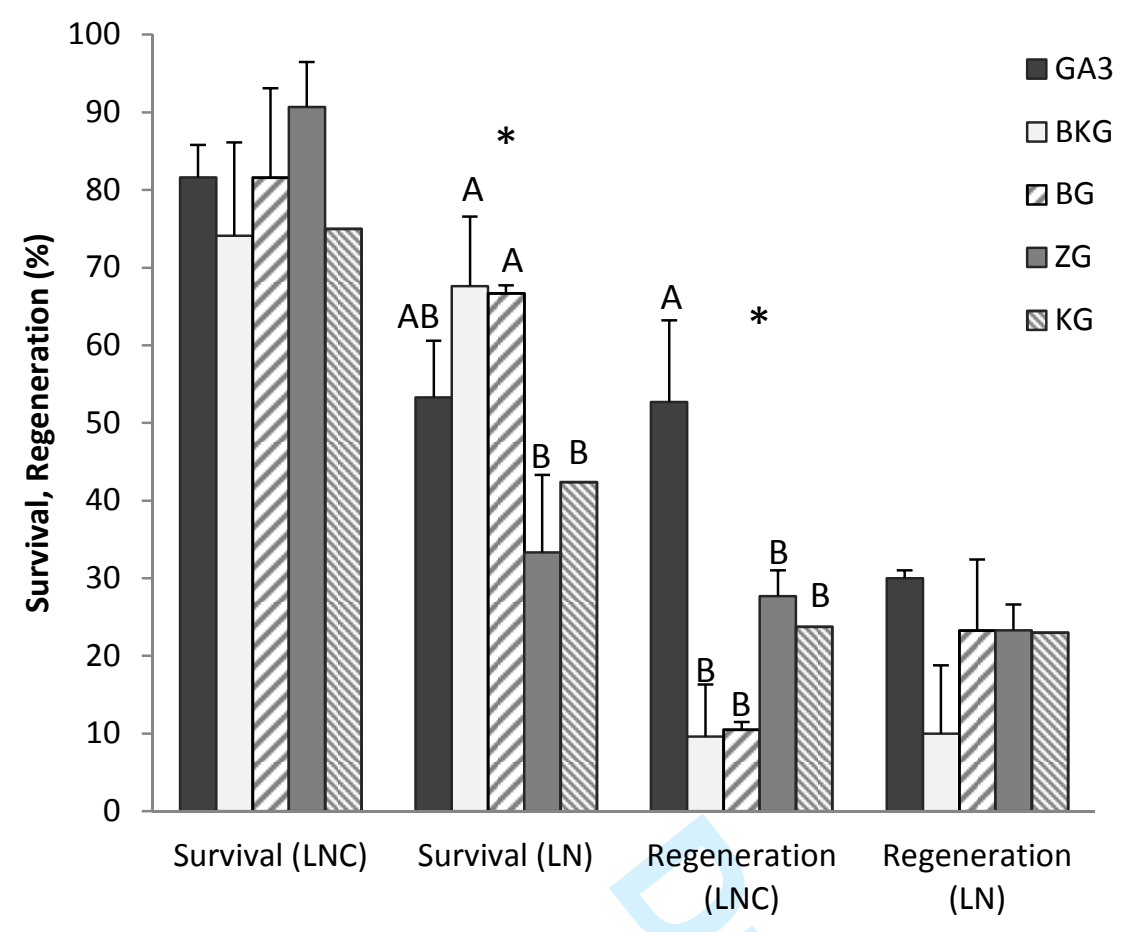

Fig. 5. 


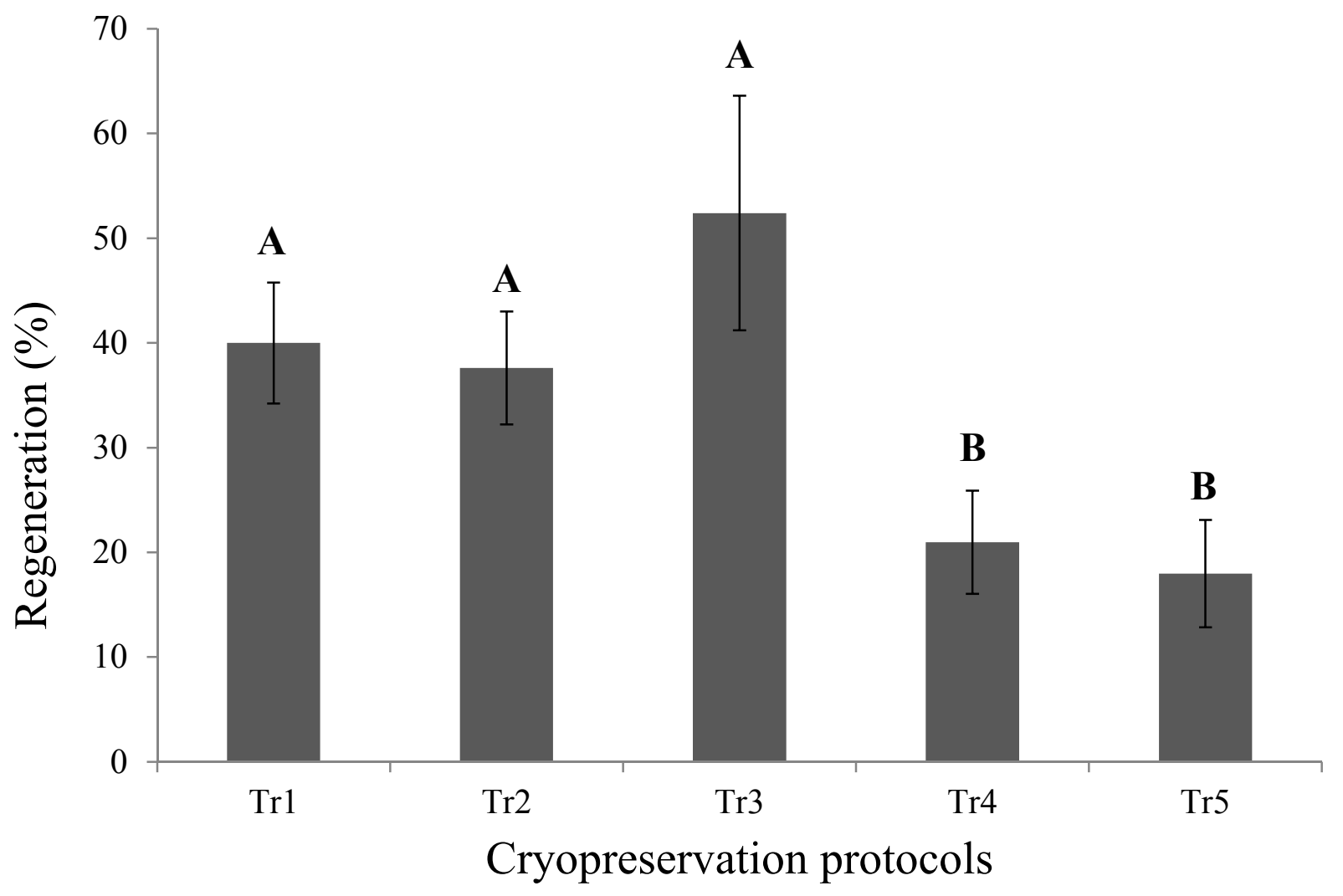

Fig. 6 


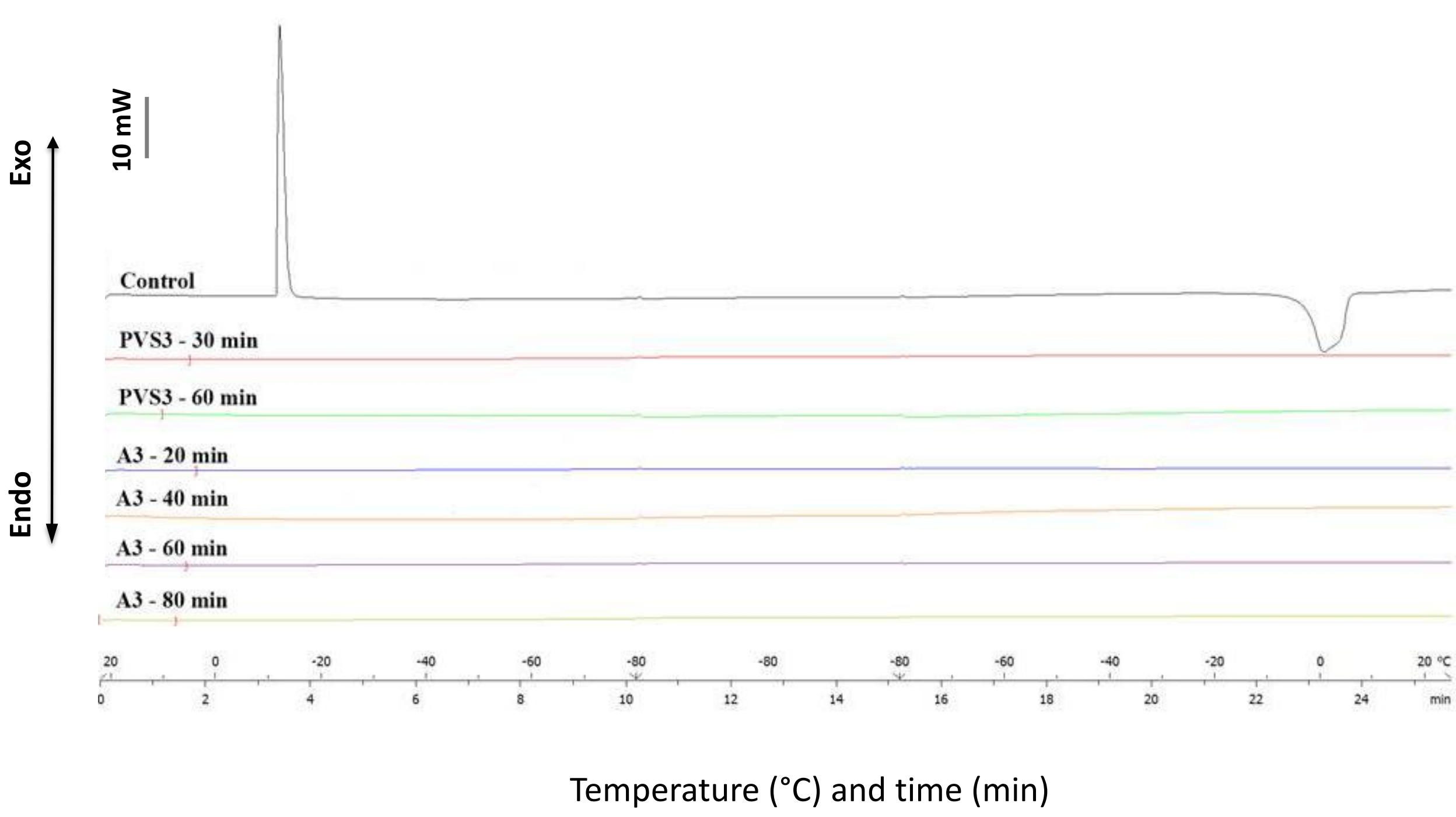

https://mc06.manuscriptcentral.com/cjfr-pubs 